\title{
A Comparative Study of the IGM Use in China's English Textbooks
}

\author{
Haiming Zhou \\ School of Foreign Languages, Yancheng Teachers University, Jiangsu 224002, China \\ Chenxiang Mao \\ School of Foreign Languages, Nanjing Normal University, Jiangsu 210046, China \\ Chunhong Ma \\ Yancheng Luminglu Junior Middle School, Jiangsu 224000, China \\ Sen Zhou \\ School of Foreign Languages, Yancheng Teachers University, Jiangsu 224002, China
}

\begin{abstract}
IGM (ideational grammatical metaphor) is frequently used in English textbooks, the application of which may influence learners' proper understanding. The present paper conducts an empirical research on the application of IGM in three English textbooks for English learners of different levels in China including junior high school, senior high school and college with a view to exploring the rate and tendency of IGM application at different levels. It is found that IGM is favored in all the textbooks and nominalization ranks the first among other types of IGM. Besides, the higher the learning level is, the more frequently IGM is used. These findings suggest that the use of IGM in the investigated textbooks turned to be appropriate for EFL learners across three different levels.
\end{abstract}

Index Terms - IGM, English textbooks, nominalization, reading ability

\section{INTRODUCTION}

Since the reading ability is an important ability that English learners should possess, it is necessary for English teachers to know how to teach reading in a more efficient way. English teachers teach reading on the basis of different kinds of English discourses, so judging the difficulty degree of an English text is of great importance for them. According to Halliday $(1999,2008)$, founder of systemic functional linguistics, grammatical intricacy is an important notion in characterizing the complexity of language. However, this notion has not yet been fully examined in the TEFL (Teaching of English as a Foreign Language) setting, particularly in EFL (English as a foreign language) textbooks. Vinh (2017) examined grammatical intricacy across textbook levels in a book series used in tertiary education in the Vietnamese context. Ferzhawana et al (2019) investigated ideational grammatical metaphor in senior high school English textbook. This study intends to examine the application of ideational grammatical metaphor (IGM) across different textbook levels to discover the difficulty degree of texts from a new perspective, with a view to exploring the rate and tendency of IGM application at different levels of English textbooks published in China.

\section{DEFINITION OF IGM}

Systemic functional linguistics approaches metaphor from the perspective of language functions. According to Thompson (2000), IGM was related to ideational function, which meant that language can be used to talk about our experience of the world, including the worlds inside our minds, to describe events and the entities involved in them. Halliday (1985, pp. 597-603) categorized grammatical metaphor into ideational grammatical metaphor and interpersonal grammatical metaphor. The former referred to the process which should have been expressed by verbs or adjectives but was expressed by nouns in fact. It also referred to taking non-process as process at semantic level and using verbs to express what should have been expressed by other word categories in form. Halliday (1996) commented that nominalization was the single most powerful resource for creating IGM. IGM mainly falls into three categories, namely verbal nominalization, adjective nominalization and verbalization.

\section{RESEARCH METHODOLOGY}

\section{A. Research Questions}

This study was undertaken to address the following questions:

(1) What is the general picture of IGM use in the textbooks for learners from junior high school, senior high school 
and college?

(2) What are the differences of the rates of IGM use in the textbooks for the above three levels of learners? Why?

\section{B. Data Collection}

Firstly, the number of sentences bearing features of verbal nominalization, adjective nominalization and verbalization will be counted by the author. The number of the IGM sentences will be counted by the author under the criterion proposed by Zhu Yongsheng (2006). Quantitative measurements of the rate of IGM use at all levels and the tendency of IGM use from junior high school to senior high school to college will be combined with qualitative discussions. To achieve this goal, the number of the use of IGM in each text will firstly be counted. Then, the rate of the use of IGM of each text will be calculated. After that, the rate of the use of IGM at each level will be calculated. Finally, the tendency of the use of IGM from junior high school to senior high school to college will be analyzed. In the following parts, the collection of data and the process of doing this research will be illustrated in detail. Table 1 reports the details of data collection.

TABLE 1

DETAILS OF DATA COLLECTION

\begin{tabular}{|c|c|c|}
\hline Types of IGM & Examples & Data collection \\
\hline Verbal nominalization & $\begin{array}{l}\text { Many things played a part in the } \\
\text { development of this new type of English. }\end{array}$ & \multirow{3}{*}{$\begin{array}{l}\text { total number of the } \\
\text { investigated forms in each text }\end{array}$} \\
\hline Adjective nominalization & $\begin{array}{l}\text { Crystal is popular with all age groups and } \\
\text { has the ability to amuse people all over the } \\
\text { world. }\end{array}$ & \\
\hline Verbalization & $\begin{array}{l}\text { In 1985, there was little rainfall in Ethiopia, } \\
\text { which led to poor harvests and the death of } \\
\text { many of the country's cattle. }\end{array}$ & \\
\hline
\end{tabular}

\section{Data Analysis}

Statistical analyses were conducted on the basis of the number of IGM sentences and that of the words in an article. The rate of IGM used in an article was calculated by the equation (the number of the IGM/ the number of the words) $\times 1000$ and the rate of IGM used in a book was calculated by the average frequency of IGM of the 15 texts. Finally, tendency of the use of IGM from junior high school to college was analyzed by the aid of EXCEL 2010 and a line chart reflecting the tendency was formulated.

\section{RESUlTS AND DISCUSSION}

This part is composed of two subparts. The first subpart provides a report of the rate of IGM used in each text as well as at each level. It also provides a report of the tendency of IGM used from junior high school to college as well as the number of the use of verbal nominalization, adjective nominalization and verbalization at each level. The second subpart presents a detailed discussion based on the data collected.

\section{A. General Description of IGM Use}

In this part, results collected are reported and analyzed, including the following aspects: the rate of IGM used in each text as well as at each level, the tendency of IGM used from junior high school to college, and the number of the use of verbal nominalization, adjective nominalization and verbalization at each level.

TABLE 2

RATE OF IGM USED IN JUNIOR HIGH SCHOOL TEXTBOOKS

\begin{tabular}{|c|c|c|c|c|c|c|}
\hline $\begin{array}{c}\text { Junior high } \\
\text { school textbooks }\end{array}$ & $\begin{array}{c}\text { The rate of } \\
\text { IGM use }\end{array}$ & $\begin{array}{c}\text { Junior high } \\
\text { school } \\
\text { textbooks }\end{array}$ & $\begin{array}{c}\text { The rate of } \\
\text { IGM use }\end{array}$ & $\begin{array}{c}\text { Junior high } \\
\text { school textbooks }\end{array}$ & $\begin{array}{c}\text { The rate of } \\
\text { IGM use }\end{array}$ & $\begin{array}{c}\text { Average rate of } \\
\text { IGM use }\end{array}$ \\
\hline Text 1 & 0 & Text 6 & 0 & Text 11 & 0 \\
\hline Text 2 & 0 & Text 7 & 6.53 & Text 12 & 3.17 \\
\hline Text 3 & 8.23 & Text 8 & 3.27 & Text 13 & 3.21 \\
\hline Text 4 & 9.4 & Text 9 & 6.53 & Text 14 & 3.23 \\
\hline Text 5 & 10.34 & Text 10 & 7.24 & Text 15 & 6.34 & \\
\hline
\end{tabular}

Table 2 shows that 11 in 15 texts taken from junior high school textbooks contain IGM and the average rate of IGM use is 4.5. Although there are 4 texts that do not contain IGM use, it does not mean that exposing second language learners to IGM is not necessary in junior high school. The average rate of IGM use shows that junior high school students have already been required to know IGM. And it is worthwhile for second language teachers to pay attention to exposing second language learners to IGM use in textbooks at junior high school level. 
TABLE 3

RATE OF IGM USED IN SENIOR HIGH SCHOOL TEXTBOOKS

\begin{tabular}{|c|c|c|c|c|c|c|}
\hline $\begin{array}{c}\text { Senior high } \\
\text { school } \\
\text { textbooks }\end{array}$ & $\begin{array}{c}\text { The rate of } \\
\text { IGM use }\end{array}$ & $\begin{array}{c}\text { Senior high } \\
\text { school } \\
\text { textbooks }\end{array}$ & $\begin{array}{c}\text { The rate of } \\
\text { IGM use }\end{array}$ & $\begin{array}{c}\text { Senior high } \\
\text { school } \\
\text { textbooks }\end{array}$ & $\begin{array}{c}\text { The rate of } \\
\text { IGM use }\end{array}$ & $\begin{array}{c}\text { Average of } \\
\text { the rate of IGM } \\
\text { use }\end{array}$ \\
\hline Text 1 & 5.56 & Text 6 & 2.98 & Text 11 & 1.5 \\
\hline Text 2 & 1.7 & Text 7 & 1.47 & Text 12 & 6.15 \\
\hline Text 3 & 3.48 & Text 8 & 2.85 & Text 13 & 3.61 \\
\hline Text 4 & 1.89 & Text 9 & 6.41 & Text 14 & 1.6 \\
\hline Text 5 & 7.91 & Text 10 & 6.12 & Text 15 & 10.2 \\
\hline
\end{tabular}

Table 3 shows that all 15 texts taken from senior high school textbooks use IGM and the average rate of IGM use is 4.2. That all 15 texts take from senior high school contain IGM use means that it puts forward higher requirements for senior high school students to understand IGM. Although the average rate of IGM use is a bit lower than that of senior high school, it does not mean that it is not important for senior high school students to be exposed to IGM. Since senior high school period is a critical period for second language learners to acquire a second language, exposing them to IGM is more important for them to activate LAD and make it work successfully in order to develop the English way of thinking and metalinguistic ability.

TABLE 4

RATE OF IGM USED IN COLLEGE TEXTBOOKS

\begin{tabular}{|c|c|c|c|c|c|c|}
\hline $\begin{array}{c}\text { College } \\
\text { textbooks }\end{array}$ & $\begin{array}{c}\text { The rate of } \\
\text { IGM use }\end{array}$ & $\begin{array}{c}\text { College } \\
\text { textbooks }\end{array}$ & $\begin{array}{c}\text { The rate of } \\
\text { IGM use }\end{array}$ & $\begin{array}{c}\text { College } \\
\text { textbooks }\end{array}$ & $\begin{array}{c}\text { The rate of } \\
\text { IGM use }\end{array}$ & $\begin{array}{c}\text { Average rate of } \\
\text { IGM use }\end{array}$ \\
\hline Text 1 & 10.2 & Text 6 & 3.68 & Text 11 & 9.43 & 3.36 \\
\hline Text 2 & 8.51 & Text 7 & 9.53 & Text 12 & 8.69 \\
\hline Text 3 & 3.52 & Text 8 & 2.77 & Text 13 & 1.73 \\
\hline Text 4 & 4.74 & Text 9 & 3.19 & Text 14 & 1.5 \\
\hline Text 5 & 1.52 & Text 10 & 14.69 & Text 15 & \\
\hline
\end{tabular}

Table 4 shows that all 15 texts taken from college textbooks use IGM and the average rate of IGM use is 5.8. From senior high school to college, all 15 texts at each level contain IGM use, which shows that IGM is used more and more frequently. As a result, teachers at senior high school level should help second language learners build a solid foundation of using IGM in order to help them keep pace with the requirement of college. Besides, the average rate of IGM use is 5.8, which is far higher than that of junior high school and senior high school. This result is also consistent with the proposition that there is a higher requirement for second language learners with age.

TABLE 5

TENDENCY OF IGM USE

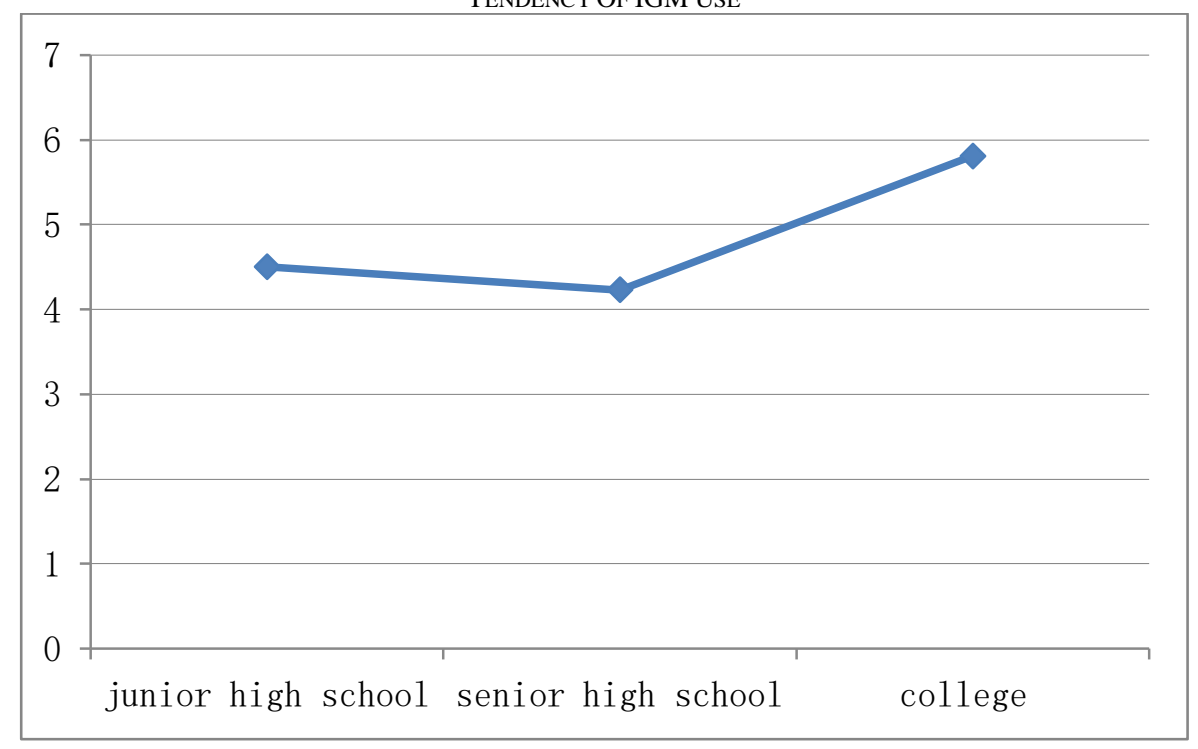

Table 5 shows that although the rate of senior high school is a bit lower than that of junior high school, the use of IGM is generally on the rise, which means that more and more IGMs are used from low grades to higher grades. And from senior high school to college, the rate of IGM use increases rapidly. From senior high school to college, second language learners are at formal operation period, which is a critical period of understanding IGM, since their abstraction ability is developed rapidly. Besides, the use of IGM is an important characteristic of academic English. As a result, senior high school English teachers should expose second language learners to more and more sentences containing IGM use and help them understand this kind of characteristic of English. By doing so, teachers can help them transit from the study of general English to that of academic English. 
TABLE 6

NUMBER OF THE USE OF THREE KINDS OF IGM

\begin{tabular}{|c|c|c|c|c|}
\hline Type & Total number of IGM & $\begin{array}{c}\text { Adjective } \\
\text { nominalization }\end{array}$ & Verb nominalization & Verbalization \\
\hline Junior high school & 20 & 8 & 12 & 0 \\
\hline Senior high school & 48 & 1 & 46 & 1 \\
\hline College & 109 & 46 & 60 & 3 \\
\hline
\end{tabular}

Table 6 shows that the total number of IGM use is on the rise and from senior high school to college the number rises rapidly. Verbal nominalization is used the most frequently at all levels and the use of it keeps rising from junior high school to college. Adjective nominalization is used the second most frequently. Verbalization is used least. As a result, teachers should help second language learners cultivate metaphorical thinking ability in order to develop their English way of thinking since English discourses always show their authors' way of viewing the world at grammatical level.

In this study, nominalization includes two cases. One is that the process is regarded as an object and represented by nouns in incongruent form, while in congruent form it is represented by verbs. This is called verbal nominalization. For example,

The police investigated the matter.

The police conducted an investigation into the matter.

The first sentence is in congruent form and includes a process. The process is expressed by the verb "investigate". The language of this sentence is distinct and easy to understand. The second sentence is in incongruent from. It changes the verb "investigate" into "investigation" which fulfills the function of object in the sentence. Through recategorization, the dynamic process becomes static, which offers people a new way of viewing the world. And English-speaking people often adopt this way to think and behave.

The other is that the quality of things is regarded as an object and represented by nouns in incongruent form, while in congruent form it is represented by adjectives. This is called adjective nominalization. For example,

I was not hungry to be free.

I was not born with a hunger to be free.

The first sentence is in congruent form and includes a quality which is expressed by the adjective "hungry". The second sentence is in incongruent form and changes the adjective 'hungry' into the noun "hunger", accordingly the attribute becomes a circumstance.

In this study, verbalization refers to taking non-process as process at semantic level and using verbs to express what is usually expressed by other word categories in form. There are four types of verbalization. The first one is to take time as a process. For example,

She left before I arrived.

Her departure preceded my arrival.

To show precedence relationship, adverbs like "afterwards" and conjunctions like "after" are used. However, in incongruent form, it is taken as a process and expressed by verbs.

The second one is to take cause and effect as a process. For example,

We rushed and so we became confused.

Our rushing led to our confusion.

The second sentence takes cause and effect relationship as a process. It is usually expressed by conjunctions, but in incongruent form, it is expressed by verbs.

The third is to take the condition as a process. For example,

I sleep with the window open unless it is really cold.

Whether I sleep with the window open is determined by the weather condition.

The first sentence is in congruent form and the condition is expressed by a conjunction. The second sentence is in incongruent form and the condition is expressed by a verb.

The last one is to take concession as a process. For example,

Ifelt he was wrong, although I did not say so at the time.

My silence did not mean that I felt he was right.

In the second sentence, the logical relationship becomes a dynamic process.

Nominalization is more recognizable and used more commonly than verbalization. That's why in the 45 texts the use of nominalization accounts for almost $100 \%$ of the whole number of the use of IGM while verbalization is used only four times.

\section{B. Detailed Discussion Based on the Data Collected}

When it comes to the general picture of IGM use, according to the five tables above, it can be concluded that IGM is used commonly from junior high school to senior high school to college and the tendency of IGM use is generally on the rise. It suggests that second language learners are required to know and understand IGM especially that existing in reading materials ever since they are in junior high school. Since the existence of IGM can make it more difficult for second language learners to comprehend the text, second language teachers should introduce IGM to them gradually, exposing them to this kind of linguistic phenomenon. By encouraging them to compare and analyze the differences 
between congruent form and incongruent form, teachers can help them understand different expressions of different discourses. Second language learners are familiar with sentences in congruent form which are direct, but they are not familiar with sentences in incongruent form. Second language teachers should help them transform sentences in incongruent form into congruent form, which will make these sentences more comprehensible. This kind of comprehensible input can activate second language learners' LAD and contribute to acquisition.

What's more, among the three kinds of IGM, verbal nominalization is used most frequently. It makes the content more concise but is not simple in fact. It makes the reading material become more difficult for second language learners to comprehend. Since verbal nominalization can be recognized more easily and exists more commonly, understanding this kind of IGM can benefit second language learners when they read English materials. And they are required to grasp this kind of IGM most. The use of language reveals the user's way of thinking, so helping second language learners recognize, understand and use IGM can develop their English way of thinking and metalinguistic ability.

When it comes to the differences of IGM use at three levels, it shows that at junior high school level, only 11 in 15 texts use IGM; while at senior high school and college level, all 30 texts use IGM. Allowing for the distinctions, it can be concluded that second language learners meet higher standards when they are in senior high school and college. And this is consistent with the cognitive developing rule of students that their thinking become more and more abstract with the increase of their age. Senior high school students and college students are at formal operational stage and their abstract logical thinking ability develops rapidly. Therefore, senior high school English textbooks and college English textbooks use more and more IGM in order to help them develop this kind of ability. The research result suggests that English teachers at junior high school level should help English learners build a solid foundation of the use of IGM in order to get them better prepared for English study in senior high school. And English teachers at senior high school level should enhance students' understanding and application of IGM in order to get them better prepared for the need of academic English in college. As to the phenomenon that the average rate of IGM use at junior high school level is a bit higher than that of senior high school level, the reasons still need to be further investigated.

Since students have been exposed to IGM since junior high school, teachers in junior high school should develop students' ability to recognize IGM. When they are teaching reading, they should tell students which sentence contains IGM and help them to paraphrase this sentence to make it in congruent form. According to Krashen's Input Hypothesis, only when comprehensible input which is a bit higher than the learner's current level is provided can it facilitate language learning. As a result, if some sentences containing IGM are not transformed into the congruent form, students will not be able to understand. Thus, the teachers need to help students paraphrase the sentence to make it much easier to understand.

Then teachers should guide students to recognize the differences between the sentence in congruent form and the sentence in incongruent form. According to Sapir-Whorf Hypothesis, there is an interdependence between language and thought. The language structure people habitually use influences the way they think and behave. Different sentences in different forms embody people's different ways of thinking and expressing the world around. By guiding students to observe the subtle differences, teachers can help them be capable of knowing how English-speaking people view and express the world. Learning a language is not only to learn its pronunciation, vocabulary, grammar, etc. but also needs to learn the way in which its users think. This will help reduce the influence of negative transfer. If students maintain the Chinese way of thinking, then what they produce will be Chinglish, which may cause confusion in cross-cultural communication.

Finally, students' ability of second language acquisition develops rapidly during senior high school according to the Critical Period Hypothesis, so teachers should help them develop metalinguistic ability. On the basis that students have learned what is IGM, teachers should help students to apply this knowledge to practice, that is, to ask students to transform the sentence in congruent form into the sentence in incongruent form and use IGM consciously in the sentences they make up on their own. Teachers should encourage students to write more sentences in incongruent form.

\section{CONCLUSION}

The present study probes into the use of three kinds of IGM, the rate of the use of IGM at three levels and the tendency of the use of IGM from junior high school to senior high school to college through quantitative analysis. Through the study, the following findings are highlighted.

First of all, as to the general picture of IGM use, IGM is used frequently at all of the three levels. That's to say, students have been exposed to IGM since junior high school. And this is consistent with Halliday's thought that people will not be exposed to IGM until they go to high school.

What's more, the rate of the use of IGM at junior high school level is a bit higher than that of senior high school level and far lower than that of college. And the tendency of the use of IGM is generally on the rise. Besides, the 30 texts taken from senior high school and college all contain IGM, which means IGM is used more and more frequently and it puts forward higher requirements for English learners at senior high school and college level.

Finally, of the three kinds of IGM, verbal nominalization as well as adjective nominalization are used the most frequently and verbalization is used the least frequently. This result is also consistent with previous studies that nominalization is used the most frequently in English texts.

In the future, more texts at different levels should be taken into consideration, which can render the findings more 
convincing. Besides, the study does not intend to exaggerate the role of IGM in English reading teaching, but to arouse the attention of teachers and students. It is hoped that this study can benefit further researches and improvement of teaching and learning English as a foreign language.

\section{ACKNOWLEDGEMENTS}

This research is supported by the Excellent Social Science Applied Research Project of Jiangsu Province (20SWB-22).

\section{REFERENCES}

[1] Ferzhawana, D., S. Ginting \& Z. Zainuddin. (2019). The Elements of Ideational Grammatical Metaphor in Reading Texts for Senior High School English Textbooks. Linguistik Terapan, 16 (3): 501-509.

[2] Halliday, M. A. K. (2008). Complementarities in Language. Beijing: The Commercial Press.

[3] Halliday, M. A. K. (1985). An Introduction to Functional Grammar. London: Edward Arnold.

[4] Halliday, M. A. K. (1996). Things and Relations: Regrammaticising Experience as Technical Knowledge in J. R. Martin \& R. Veel (eds.) Reading Sciences: Critical and Functional Perspectives on Discourse of Science. London: Edward Arnold.

[5] Halliday, M. A. K. (1999). The Grammatical Construction of Scientific Knowledge: The Framing of English Clause, in J. J. Webster (ed.) The Language of Science. Beijing: Peking University Press. 101-132.

[6] Thompson, G. (2000). Introducing Functional Grammar. Beijing: Foreign Language Teaching and Research Press.

[7] Vinh, T. (2017). Grammatical Intricacy in EFL Textbooks. International Journal of English Language Education, 5 (2): 127-140.

[8] Zhu Yongsheng. (2006). On Nominalization, Verbalization and Grammatical Metaphor. Foreign Language Teaching and Research, 38 (2): 83-90.

Haiming Zhou, $\mathrm{PhD}$, is an associate professor at the School of Foreign Languages, Yancheng Teachers University, P. R. China. His research interests include teaching English as a foreign language, systemic functional linguistics and effective English language pedagogy for high school education in P. R. China.

Chengxiang Mao is an M. Ed. candidate at the School of Foreign Languages, Nanjing Normal University, P. R. China. Her research interests include English education and applied linguistics.

Chunhong Ma is a senior teacher at Yancheng Luminglu Junior Middle School, Jiangsu Province, P. R. China. Her research interest includes English textbooks and curriculum design.

Sen Zhou is a B. A. candidate at the School of Foreign Languages, Yancheng Teachers University, P. R. China. His research interest includes English education. 